\title{
Peertechz
}

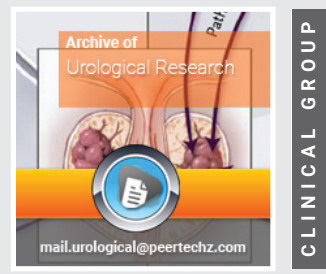

\section{Urinary continence:}

\section{Experience of a single}

\section{departement with 136 cases}

\section{Hanaa Khir Allah*, Aiat Allah Skiredj, Freddy Niyongere, Mohamed Rami, Rachid Belkacem and Mohamed Amine Bouhafs}

Pediatric Urology Department, Rabat Children's Hospital, Ibn Sina UHC, Mohammed V University, Medical Faculty, Rabat, Morocco
Received: 22 April , 2020

Accepted: 08 May, 2020

Published: 09 May, 2020

*Corresponding author: Dr. Hanae Khir Allah, Pediatric Urology Department, Rabat Children's Hospital, Ibn Sina UHC, Mohammed V University, Medical Faculty, Rabat,

Morocco, Tel: +212641612870;

E-mail: Hanae8903@gmail.com

ORDID: https://orcid.org/0000-0001-9222-0753

Keywords: Bladder extrophy; Continence; Factors https://www.peertechz.com

Check for updates

\section{Abstract}

Purpose: We performed a retrospective review of patients with bladder Extrophy, to analyse long term outcomes of bladder neck reconstruction and evaluate factors influencing urinary continence.

Materiels and methods: We reviewed the chart of 136 patients treated for bladder extrophy Epispadias complex, at our institution from 2000 to 2019.

Mitchell bladder neck reconstruction technique was performed in all patients, including Mitrofanoff's procedure in 20 patients and bladder augmentation in 15 patients.

Criteria for good outcome in terms of continence are defined and factors influencing continence results are reviewed.

Results: Data from our series showed continence following successful Bladder neck reconstruction(BNR) was excellent in $37 \%$ of patients .This increased to $72 \%$ after Mitrofanoff's procedure.

Most patients ( $57 \%$ )had good results $4 \%$ of patients a poor result.

Conclusion: Successful initial bladder closure , bladder capacity, and type of bladder neck reconstruction, have an important impact on management of bladder exstrophy

\section{Introduction}

The treatment of patients with incontinence secondary to congenital defects such as the exstrophy- epispadias complex is one of the greatest technical challenges facing urologic reconstructive surgeons [1].

Urinary continence with preservation of renal function is a major treatment goal . To coordinate continence, the surgeon must balance the bladder pressure and the degree of outlet resistance. Along with successful initial closure of the bladder and early epispadias repair, adequate bladder growth and capacity are key elements in achieving urinary continence [2].
The Young-Dees-Leadbetter technique and its modifications are considered the reference standard for BNR in children with bladder exstrophy [3].

\section{Materiels and methods}

We reviewed the charts of 136 patients treated for bladder extrophy epispadias complex, at our institution from 2000 to2019.

All patients underwent Mitchell bladder Neck reconstruction technique, including Mitrofanoff's procedure in 20 patients , and bladder augmentation in 15 patients. 
Criteria for good outcomes in terms of continence are defined and factors influencing outcomes are reviewed.

Charts were reviewed to determine patient's age at bladder closure, preoperative and postoperative bladder capacity, age of bladder neck repair, adjunct interventions, continence status, and complications.

Primary bladder closure was the initial surgical procedure in 106 boys and 30 girls $(\mathrm{M} / \mathrm{F}=3.6)$. Patients underwent bladder closure between 24 hours of birth and 2 years. (median age was 3months).

Osteotomy was performed in 12 patients, it was systematically done in infants operated on late ( $>=8$ months) or there was redo after dehiscence, or bladder template was $>=$ $8 \mathrm{~cm}$ under anesthesia examination. we used Salter Osteotomy since 2015, pubic rami osteotomy was performed only on one case. Epispadias repair was performed at a median age of 20 months (range 12 to 63 months).

Bladder capacity was measured by Cystourethrogram Voiding(VCUG) in pre operative evaluation, the average was 94 cc (range 30-130cc).Mean patient age at Bladder Neck Reconstruction was 5 years and 6 months (range 4-16 years), they underwent Mitchell's technique. concomitant bladder augmenation using ileal pouch was performed for patients, with bladder capacity < $30 \mathrm{ml}$ (15 patients), it used till 2011,since then abandoned because of risk and complications.

Mitrofanoff's procedure was performed in 20 patients, systematically combined with enteroplasty, and in 5 cases of poor bladder capacity and bad quality of bladder tissue after a redo bladder closure

this procedure was used systematically during 2001-2002 to increase Bladder neck resistance ; BNR using a 6 fr catheter and was considered as a sowny access to bladder.

The follow-up period ranged from 6 to 19 years. It consisted of regular office visits, in which detailed patient histories were reviewed and physical examinations were performed. Patients also underwent frequent urine analysis, serum creatinine, and ultrasound evaluations.

Anticholinergic treatment was prescribed in all patients after surgery, to promote badder compliance and urinary continence.

\section{Criteria of continence outcome in our study}

\begin{tabular}{|c|c|c|c|}
\hline Dryness(continence) & diurnal & nocturnal & Urinary state \\
\hline Excellent & $\begin{array}{c}>3 \mathrm{~h} \text { even effort and } \\
\text { sport }\end{array}$ & No pads & No dilated \\
\hline Good & $>2 \mathrm{~h}$ even effort & No pads & No dilated \\
\hline Acceptable & $>1 \mathrm{~h}$ no pads & No pads & No dilated \\
\hline Bad results & $<1 \mathrm{~h}$ pads & No pads & No dilated \\
\hline
\end{tabular}

\section{Operative procedure: Mitchell bladder neck reconstruc- tion technique}

In this technique, the anterior urethra is incised transversally and the incision is extended cephalad.
The incision is made full thickness. After trigono cephalic ureteral reimplantation Figure 1 the urethral strip is tubularized in two layers using a Vicryl suture (4-0 or 5-0) over an 8 or 6 French urethral catheter, depending on the size of the patient and associated Mitrofanoff or not Figure 2.

The bladder may be closed in continuity with the urethral closure. This procedure effectively narrows and lengthens the urethra. It also moves fibrotic tissue at the level of the original bladder neck away rom the new bladder neck [4].

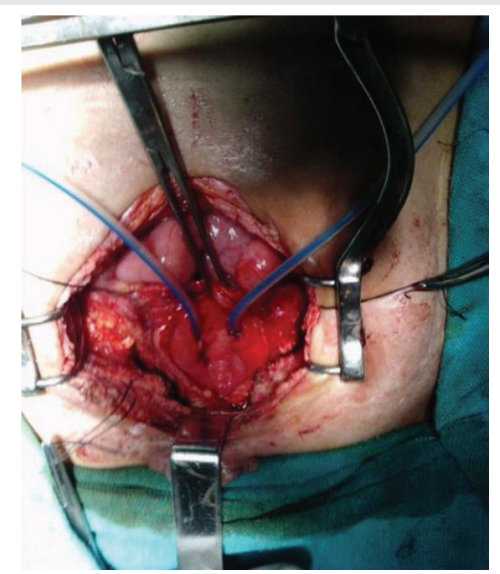

Figure 1: Trigono cephalic ureteral reimplantation.

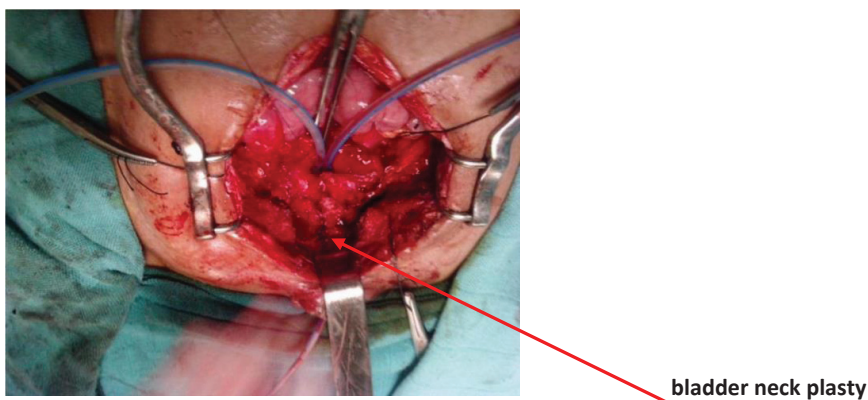

Figure 2: The urethral strip is tubularized in two layers using a Vicryl suture (4-0 5-0) over an 8 French urethral catheter.

\section{Results}

Gender seemed to be a factor success of BNR, we reported $94 \%$ continent female compared to $69 \%$ male.an excellent result was obtained in 40 patients who underwent bladder closure at a median age of 72 hours of birth (75\%), and a good result $(60 \%$ )was achieved in patients with initial closure after 72 hours.

15 patients had Failed initial bladder closure, 8 patients required bladder augmentation at the time of BNR, rate of continence was only $45 \%$.

Age of BNR have a most impact, patients who underwent BNR before 5 years, had more difficulty acheiving continence.

The patients who had preoperative bladder capacity over than $90 \mathrm{ml}$, had good results of continence ( $82 \%$ ) compared to other patients Figure 3 
impact of bladder capacity on dryness results

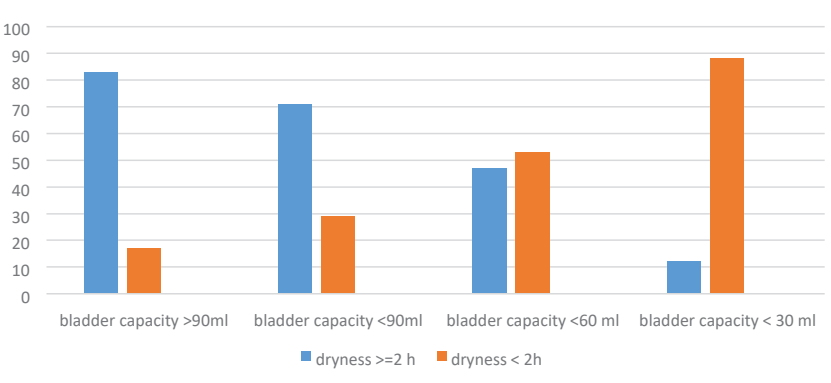

Figure 3: Impact of bladder capacity on dryness results.

Data from our series showed that continence following successful BNR was excellent in $37 \%$ of patients.

Most patients (57\%) had good results, $4 \%$ of patients experienced a poor result, they had failed staged exstrophyepispadias repair, Repeat Bladder neck reconstruction was performed without improvement of continence .

Mitrofanoff's procedure was performed in 20 patients ; to facilitate bladder emptying ,all of them had good results. (dryness $>2$ hours)

The most common complications were bladder stone formation (24 patients), urinary fistula (15 patients), and stenosis of neck plasty ( 9 patients), Urinary infection was encountered in 6 patients, while cystitis and asymptomatic bacteriuria in 32 patients . Renal failure was occured in 3 cases, 2 patients were continent ( $>3$ hours), the first one was 19 years old, she didn't use the clean intermittent catheterization for several years, and the second was lost for 3 years.

The third one had a probable aminosid nephrotoxicity.

No one of these renal failure had bladder augmentation.

\section{Discussion}

Bladder exstrophy remains one of the most challenging conditions managed by pediatric urologists. Although rare, this disorder imposes significant physical, functional, social, sexual and psychological burdens on patients and families [5].

The reconstructive concept is based on the fundamental agreement that the exstrophic bladder has the potential ability to gain normal bladder function as a low-pressure reservoir for urine storage, active voiding and upper urinary tract protection after functional reconstruction [6].

Bladder functions of storage and emptying are influenced greatly by several bladder qualities and characteristics, such as capacity, compliance, contractility, and coordination. Ultimately, when normal, these characteristics help provide urinary continence [7].

\section{Bladder Neck Reconstruction (BNR)}

Numerous techniques for Bladder Neck Reconstruction
(BNR) were described to increase outlet resistance in patients with bladder exstrophy. The Young-Dees-Leadbetter technique and its modifications are considered the reference standard for BNR in children with bladder exstrophy [3].

Lottmann, et al. [8], presented long-term follow-up of Cendron's patients with the exstrophy complex who underwent complete reconstruction. With the Young-Dees repair they were able to achieve a urinary continence in $71 \%$ of male patients and $53 \%$ of female patients. Overall, total continence was $65 \%$ with a mean follow-up of 12 years after BNR.

In our series, all of the patients underwent Mitchell bladder neck reconstruction technique ,we had excellent results in $37 \%$ of patients. Most patients had good results (57\%).

The more the patient is continent, the more we should be carefull with the urinary tract dilatation and renal risk.

We found many factors influencing urinary continence results; Gender seemed to be a factor success of BNR, we reported $94 \%$ continent female compared to $69 \%$ male.

Bladder neck reconstruction (BNR) is a continence procedure that is typically performed when a patient is 5-8 years of age and has a strong desire to be continent. The patient must be mentally prepared to commit to an intense voiding program [2].

In our series, the patients who underwent BNR before 5 years , had more difficulty acheiving continence.

The patients who had preoperative bladder capacity of $90 \mathrm{ml}$, had good results of continence, $82 \%$ of patients had dryness $>2$ hours, in comparison with the other patients who had bladder capacity $<60 \mathrm{ml}(54 \%)$.

Concomitant bladder augmenation was performed for patients with bladder capacity $<30 \mathrm{ml}$ (15 patients), all of them are continent because BNR over a 6 fr catheter.

Bladder augmentation using ileal pouch was used till 2011. since then abandoned, because of risk and complications. Mitrofanoff's procedure was performed in 20 patients ; to facilitate bladder emptying ,all of them had good results (dryness $>2$ hours)

This procedure was used systematically during 2001-2002 to increase Bladder neck resistance, BNR using a 6 fr catheter and was considered as a access to bladder.

\section{Complications of BNR}

Failed BNR: The reasons for failure of primary or secondary BNR are numerous.

John P and Gearhart [9], In careful analysis of patients, found 4 probable causes of failure of the bladder neck procedures. 2 patients had dehiscence secondary to infection of BNR and complete failure to achieve continence. 5 patients who had undergone a bladder neck procedure with a capacity of less than $60 \mathrm{cc}$ had inadequate initial capacity for the 
procedure, 10 patients did not achieve sufficient resistance and continued to leak urine after Bladder neck procedure. This condition probably results from the fact that initial BNR was not tight enough to allow for adequate resistance .The wide intersymphyseal distance and soft intersymphyseal area that make BNR difficult was another reason for failure to acheive continence.

We think that intersymphyseal distance occurs after osteotomy no matter, the material of fixing this led as to abandon osteotomy, it only used for patients over 9 months or sever dehiscence $>10 \mathrm{~cm}$ at redo procedure.

Bladder stones: Vesical calculus in EB repaired patients is known to occur. Many of the stones develop on the suture material used for the repair which is mostly nonabsorbable. Bladder neck obstruction with resultant stasis and infection in EB repaired patients predisposes to stone formation [10]

In a study of 530 patients with EB, 15\% developed stones; white male population was the most commonly affected group and most calculi formed in the urinary bladder whether native or augmented by enterocystoplasty [4]. It was also noted that the risk of stone formation in EB patients was associated with operative procedures like augmentation cystoplasty and bladder neck procedure to increase the outlet resistance; other risk factors being urinary infection, foreign bodies, vesicoureteral reflux and urinary stasis [10].

In our series, 15 patients had bladder stone, recurrence in 9 patients, 2 patients had neocervical staghorn calculus ; one of them became incontinent after calculus ablation.

\section{Predictor factors influencing urinay continence}

Size of bladder template: Reasons that the bladder may fail to increase in capacity include a small bladder template. alteration of the collagen ratios (which causes poor bladder compliance) and alterations at a cellular level in growth factors responsible for bladder growth. These patients constitute a group that is unable to achieve continence per urethra [11].

Baker and Gearhart [12], suggested if an examination under anesthesia reveals a small $(<5 \mathrm{~cm} 3)$ acontractile and no distensible bladder, an attempt should not be made to close this bladder, their preference is to wait and reexamine the child at $4 \pm 6$ months of age under anesthesia.

In our study, $60 \%$ of patients whose had adequat size of bladder template $>20 \mathrm{~cm} 2$, developped satisfactory bladder capacity ( > $90 \mathrm{cc}$ ) at the time of Bladder Neck Reconstruction.

Initial bladder closure: One of the primary aims in the surgical management of bladder exstrophy is to secure bladder and abdominal- wall closure without tension. Primary bladder closure is the first procedure (after osteotomy in indicated cases) in a staged approach for bladder exstrophy [13]. There is no doubt that early and successful primary bladder closure plays a pivotal role in achieving a continent bladder in exstrophied children. This is highlighted by the fact that patients with successful initial bladder closure without bladder dehiscence and prolapse have the largest bladders at the time of bladderneck reconstruction (BNR) (mean capacity $79 \mathrm{ml}$ ), the shortest interval between primary closure and BNR (mean 3.5 years), the highest urinary continence rate (92\%), and the shortest interval between BNR and achievement of urinary continence (mean 1.5 years) after primary bladder closure [13].

In our study, early bladder closure was performed in 40 patients , they had excellent result of continence (75\%) Figure 4 .

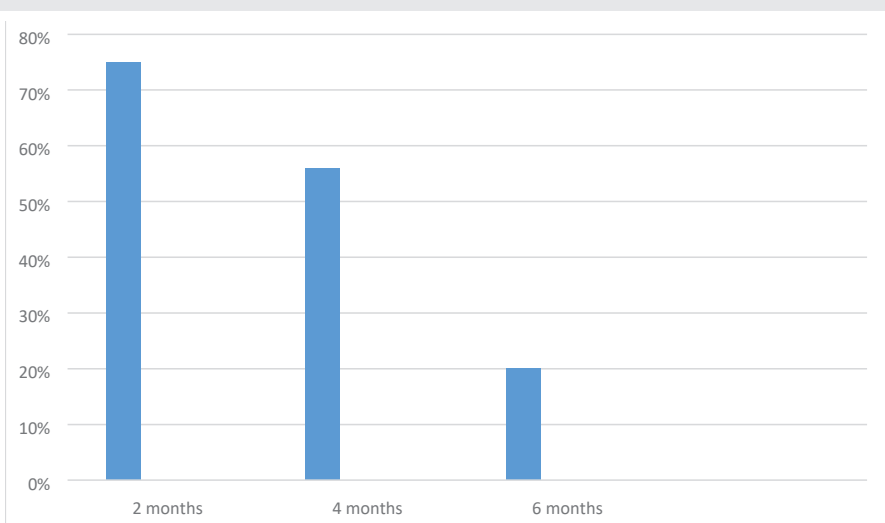

Figure 4: Impact of initial bladder closure on dryness results.

Failed initial extrophy closure: The consequences of a failed primary closure are serious not only in terms of the requirement for a redo closure, but also in terms of the potential negative impact on the future development of bladder capacity and continence [14].

Primary closure of bladder exstrophy tends to fail during the immediate postoperative period by one of the following modes : wound dehiscence, bladder prolapse, bladder outlet obstruction, or vesicocutaneous fistula. Proper immobilization of the pelvis as described above, along with adequate sedation and pain control, have been shown to decrease the rate of postoperative complications and failure of closure [15].

Anticholinergics dramatically decreased bladder dehiscence in our experience.

In a series reference of failed exstrophy closures,122 patients had undergone repeat closure following failure, In comparison to patients with successful primary closure, the rates of urethral continence following successful repeat closure were lower ; $83 \%$ success rate of BNR in children who had successful primary closure , By comparison, only $42 \%$ success of BNR in children who had failed at least one attempt at closure.This disparity highlights the substantial impact of a failed closure [16]

In our series, failed bladder closure was encountered in 15 patients, they underwent bladder closure after 72 hours of birth.

9 patients had a subsequent dehiscence , 5 of them in spite of osteotomy ( salter in 3 patients and pubic rami in 2) 
Since we started using anticholinergics and insisting on perfect analgesia, we have less than $5 \%$ dehiscence).

Bladder capacity and compliance: Bladder functions of storage and emptying are influenced greatly by several bladder qualities and characteristics, such as capacity, compliance, contractility, and coordination [7]. Several urodynamic series confirmed the abnormal bladder profile in the exstrophy group, with poor compliance, small capacity and unstable contractions, which could also explain persistent incontinence in some patients [17]

Chan, et al. [18], have shown that children with a capacity of $>85 \mathrm{~mL}$ have better outcomes than children with capacities $<85 \mathrm{~mL}$.

In a series from North America reference using mainly the classic Young-Dees-Leadbetter repair, reported continence, ranging from $75 \%$ to $82 \%$. The most important long-term factor gleaned from the review of all these series is that bladder capacity at the time of BNR is a very important determinant of eventual success [18].

Eric Z [19], demonstrated that absolute bladder capacity was the best way to evaluate which patients are candidates for BNR after failed closure and was the only variable predictive of successful outcome.

In our series, we occured that bladder capacity was $>90 \mathrm{ml}$ in $20 \%$ of patients and it was less than $60 \mathrm{ml}$ in $42 \%$ of them.

Enteroplasty and Mitrofanoff's procedure were performed if bladder capacity was $<30 \mathrm{ml}$. in the case where bladder capacity was between $30 \mathrm{ml}-60 \mathrm{ml}$; we associeted BNR and anticholinergics . poor capacity bladders are at high risk of urinary tract dilatation , $85 \%$ of dilatation of urinary tract occured in bladders of less than $60 \mathrm{ml}$ of capacity, therefore during a period we combined Mitrofanoff to BNR in 5 patients to facilate urin drainage.

Catheterisable continent urinary diversion: Continent Catheterizable Conduit (CCC), namely a conduit of Mitrofanoff or an equivalent is performed to facilitate bladder emptying clean intermittent catheterization (CIC), which protects the upper urinary tract and improves continence by allowing a strait BNR [18].

The continent stoma provides a means to reduce residual urine during bladder training. Furthermore, bladder neck reconstruction-Continent stoma is a suitable alternative in patients with a prior failed exstrophy closure, who have sufficient bladder growth to protect against potential contractility issues. Patients who present with an obstructive pattern of voiding postBNR may use the Continent stoma to empty their bladders completely [2].

The use of intermittent bladder lavage via the catheterization duct reduces bladder stones by $80 \%$ or more, their risk factors are metabolic disorders, chronic bacterial colonization and mucus production, but no study has evaluated the long-term evolution of this practice [19].
In our series, excellent results were reported in $76 \%$ of patients who underwent BNR associated to clean intermittent catheterization, probably because BNR was very narrow ( $6 \mathrm{fr}$ catheter ) but $80 \%$ had stenosis of bladder neck.

Bladder augmentation: The size of the bladder at the time of surgery dictates whether an outlet procedure along with bladder augmentation and continent stoma can be accomplished, or if the bladder neck will need to be transected, and augmentation and a continent stoma required [20].

Despite a satisfactory initial closure, some bladders never attain sufficient capacity for normal function. It has become clear that multiple bladder closures, bladder prolapse, dehiscence, bladder calculi, recurrent infections, and vesicostomy have a negative impact on the potential of the exstrophy bladder. Bladder augmentation is recommended in this situation.

If the patient does not respond to the initial closure, chances for successful reconstruction without augmentation are significantly reduced [21]

Snodgrass, et al. [3], advocated BNR without augmentation for neuropathic incontinence, regardless of the bladder capacity. However, it is unknown whether this concept applies to patients with bladder exstrophy, their data had shown that all patients who had undergone concomitant bladder augmentation were continent using CIC. However, the longterm complications of intestinal bladder augmentation should be considered.

No one of our patients underwent a delayed bladder augmentation, but most of them are prescribed anticholinergics for years.

10 patients with dilatation undewent a cystoscopy to eliminate a tight BNR. We withingly avoid enteroplsty for its complications.

\section{Urinary diversion}

Achievement of urinary continence in children with bladder exstrophy is a surgical challenge. Although numerous options are available, none is ideal and none has predictable outcomes in different hands. The idea of an anal sphincter-controlled bladder substitute as a treatment option for bladder exstrophy became a reality in the 19th century. The primary enthusiasm was followed by disappointment owing to the serious drawbacks of ureterosigmoidostomy, such as hyperchloremic metabolic acidosis in $80 \%$ of patients, ureterocolic stricture in $30 \%$, pyelonephritis in $20 \%$, and a delayed occurrence of colonic carcinoma at the ureterocolic anastomotic site in $6 \%$ to $29 \%$ Moreover, decreased linear growth and osteopenia were reported with long-term follow-up. Currently, the procedure and its modifications have been nearly abandoned [3]. in our series, no patient underwent urinary diversion.

\section{Bulking agents injection}

Enhancing bladder outlet resistance can theoretically be achieved by injecting biocompatible bulking agents in the region of the bladder neck, or lower in the urethra [17]. 
The series by Duffy and Ransley [17], in 12 patients with posterior epispadias after reconstruction of the penis showed three successes and six improved after a mean follow-up of 10 months. The series by Lottmann, et al. [8], included a mixed population with neuropathic bladder exstrophy, epispadias and ectopic ureters. They reported improved continence in $46 \%$ of those with exstrophy and an increase in bladder capacity in up to half of them.

We still are seeking for bulking agent injections (Deflux *, Macroplastic *).to improve continence and Volitional voiding.

\section{Conclusion}

Determinants of continence in the bladder exstrophy population are multifactorial [22-25]. Initial adequate bladder closure, even when delayed or repeated, pelvic osteotomy and bladder neck reconstruction performed by an experienced surgeon are essential. In addition, a compliant, large capacity bladder helps achieve urinary continence. When bladder capacity and compliance are poor, bladder augmentation with clean intermittent catheterization is an acceptable alternative but should be considered only when reconstruction fails and should not be performed in a patient who is too young [8].

\section{References}

1. Fernando A, Ferrer, Yousef E, Tardos, Gearhart J (2001) Modified young dees leadbetter bladder neck reconstruction: new concepts about old ideas. Urology 58: 791-796. Link: https://bit.ly/3biPwEp

2. Kasprenski M, Benz K, Jayman J, Lue K, Maruf M, et al. (2018) Combined Bladder Neck Reconstruction and Continent Stoma Creation as a Suitable Alternative for Continence in Bladder Exstrophy: A Preliminary Report. Urology. Link: https://bit.ly/2WeUKNy

3. Hafez AT (2011) Detrusor Wraparound for Bladder Neck Reconstruction in Cohort of Children With Bladder Exstrophy. 78: 881-885. Link: https://bit.ly/2Wi4GG5

4. Nelson CP, Dunn RL, Wei JT (2005) Contemporary epidemiology of bladder exstrophy in the United States. J Urol 173: 1728-1731. Link: https://bit.ly/2Ab1SIp

5. Steven GD, Canning D, El-Khoury A, Pippi JLS (2019) The Kelalis-KingBelman textbook of clinical pediatric urology. Sixth edition Boca Raton : CRC Press 1477. Link: https://bit.ly/2SGxi9F

6. Ebert KA, Reutter H, Ludwig M, Wolfgang HR (2009) The Exstrophyepispadias complex. Orphanet J Rare Dis 4: 23. Link: https://bit.ly/3cidzEQ

7. Borer JG (2011) The use of bladder neck reconstruction in bladder Exstrophy Semin Pediatr Surg 20: 91-96. Link: https://bit.ly/2yD5oEE

8. Lottmann HB, Melin Y, Cendron M, Lombrail P, Beze-Beyrie P, et al. (1997) Bladder Exstrophy: Evaluation of factors leading to continence with spontaneous voiding after staged reconstruction. J Urol 158: 1041-1044. Link: https://bit.ly/2YQfoVX

9. Chalmers D, Ferrer F (2011) Continent urinary diversion in the epispadias-exstrophy complex. Semin Pediatr Surg 20: 102-108. Link: https://bit.ly/3fF3ofU
10. Gearhart JP, Canning DA, Jeffs RD (1999) failed bladder neck reconstruction options for management. J Urol 46: 1082-1084. Link: https://bit.ly/2YLIOV0

11. Gearhart JP, Mathews R (1997) The Exstrophy-Epispadias Complex Research Concepts and Clinical Applications. Proceedings of the First International Syeposlue on Exstrophy and Eplspadlas. Springer Science+ Business Media, LLC. In Baltleore. Maryland . 242.

12. Baker LA, Gearhart JP (1998) The staged approach to bladder exstrophy closure and the role of osteotomies. World J Urol 16: 205 -211. Link: https://bit.ly/3fxKgQC

13. Kasat LS, Borwankar SS (2000) Borwankar Factors responsible for successfu primary closure in bladder exstrophy. Pediatr Surg Int 16: 194-198. Link: https://bit.ly/2LaUYPg

14. Mushtaq I, Garriboli M, Smeulders N, Cherian A, Desai D, et al. (2013) Primary Bladder Exstrophy Closure in Neonates: Challenging the traditions. J Urol 191. Link: https://bit.ly/2SMy2de

15. Massanyi EZ, Gearhart JP, Kost-Byerly S (2013) Perioperative management of classic bladder exstrophy. Res Rep Urol 5: 67-75. Link: https://bit.ly/3ciiRR0

16. Novak TE, Costello JP, Orosco R, Sponseller PD, Mack E, et al. (2009) Failed exstrophy closure: Management and outcome.

17. Duffy PG, Ransley PG (1998) Endoscopic of urinary incontinence in children with primary epispadias. Br J Urol 81: 309-311. Link: https://bit.ly/2Ab4f7N

18. Massanyi EZ, Shah BB, Baradaran N, Gearhart JP (2013) Bladder capacity as a predictor of voided continence after failed exstrophy closure. J Pediatr Urol 10. Link: https://bit.ly/3ch3Gr3

19. Faure A, Cooksey R, Bouty A, Woodward A, Hutson J (2016) Bladder continent catheterizable conduit (the Mitrofanoff procedure): Long-term issues that should not be underestimated. 52: 469-472. Link: https://bit.ly/2Wf30Sm

20. Hensle TW, Bingham J, Lam J, Shabsigh A (2003) Preventing reservoir calculi after augmentation cystoplasty and continent urinary diversion: the influence of an irrigation protocol. BJU Int 93: 585-857. Link: https://bit.ly/3fuBWkG

21. Surer I, Ferrer FA, Baker LA, Gearhart JP (2003) Gearhart.continent urinary diversion and the Extrophy - Epispadias Complex. J Urol 169: 1102-1105. Link: https://bit.ly/2yGv7fg

22. Lottmann HB, Margaryan M, Bernuy M, Rouffet MJ, Bau MO, et al. (2002) The effect of endoscopic injections of dextranomer based implants on continence and bladder capacity: a prospective study of 31 patients. J Urol 168: 1863 1867. Link: https://bit.ly/2YLAfK2

23. Mouriquand PD, Bubanj T, Feyaerts A, Jandric M, Timsit M, et al. (2003) Long term results of bladder neck reconstruction for incontinence in children with classical bladder exstrophy or incontinence epispadias. BJU Int 92: 997-1001. Link: https://bit.ly/2zkFDJn

24. Chan DY, Jeffs RD, Gearhart JP (2001) Determinants of continence in the Bladder continence in the Bladder Extrophy Population : predictors pf success 57: 774-777. Urology Link: https://bit.ly/2xIAkmn

25. Hai A, Sinha A, Bisht M, Gola N (2011) Erosion of repaired exstrophy bladde by a large vesical calculus. J Indian Assoc Pediatr Surg 16: 102-103. Link: https://bit.ly/3dsfAyx 